\title{
Scoliosis Induced by Medullary Damage: An Experimental Study in Rabbits
}

\author{
CARLOS BARRIOS, MD,* MARÍA T. TUÑÓN, MD,† JOSÉ A. DE SALIS, MD,* \\ JOSÉ L. BEGUIRISTAIN, MD,* and JOSÉ CAÑADELL, MD*
}

From the *Department of Orthopaedic Surgery, Navarra University Clinic, and the †Department of Pathology, Hospital of Navarra, Pamplona, Spain.

Presented at the First Congress of the European Spinal Deformities Society, Rome, April 1986.

Supported by The Research Committee of the Navarra University Clinic and The Echebano Fondation.

\begin{abstract}
To date, there have been no reports of experiments designed to induce scoliosis by direct damage of different areas of the spinal cord. In a series of rabbits with medullary damage, the authors attempted selectively to interrupt the pathways that mediate proprioceptive input. Unilateral lesion of the dorsal column and posterior horn of the spinal cord was performed using three different techniques: coagulation with laser, stereotaxic microcoagulation, and longitudinal electrocoagulation. Of 32 operated rabbits, 17 developed scoliosis, exhibiting clear pathologic damage of the spinal cord. Electrophysiologic study, including EMG and analysis of the tonic - vibratory reflex, was performed on 10 rabbits with medullary damage (scoliotic and nonscoliotic) and 12 matched controls. The data suggest disturbance of the sensory afferences that control the postural tone and consequent muscular imbalance, expressed as reduced activity in the muscles of the convex side. This work supports the view that loss of proprioceptive neural impulses caused by medullary damage can induce scoliosis.
\end{abstract}

\section{KEY WORDS}

experimental scoliosis, proprioception, spinal cord, electromyography 


\section{INTRODUCTION}

Deficient maturation or abnormality of the central nervous system, involving different levels, has been proposed as the cause of idiopathic scoliosis. ${ }^{12,20}$ Some clinical findings point to disorders in the integration of sensory afferences, especially proprioceptives, as causing scoliosis. ${ }^{2,17,22}$ Paraspinal muscle imbalance and defects in the control of the postural tone and equilibrium may act as a trigger mechanism. ${ }^{16,21}$ Cadaver studies have suggested that failure of the spinal cord to rotate with the vertebrae and consequent traction on the nerve roots, leading to degeneration of the dorsal root ganglion cells, may induce progression of idiopathic scoliosis., ${ }^{9,13}$

In experiments, unilateral transection of the dorsal roots of the spinal nerves can be used to induce scoliosis in rabbits and primates. ${ }^{8,10,15}$ The proportion of animals affected and the degree of scoliosis increases as the number of nerve roots transected increases. The obtained curves were convex toward the damaged side. Pincott and Taffs ${ }^{14}$ observed that some primates that had undergone virulence testing for poliomyelitis virus developed scoliosis. Histologic examination of the spinal cord in the scoliotic primates revealed greater damage to the posterior column, compared with nonscoliotic animals. Thus, damage to the sensory pathways within the spinal cord was considered significant in the development of scoliosis. It was concluded that scoliosis may develop as a result of asymmetric muscle weakness, following the loss of proprioception.

To our knowledge, scoliosis has not been induced in experimental animals by surgical damage to selected areas of the spinal cord. Our goal in this study in rabbits was to investigate whether scoliosis could be induced by intramedullary posterior lesions. We damaged the spinal cord using an original technique that attempts to interrupt selectively the intramedullary pathways that mediate the proprioceptive input. In addition, we evaluated the effects of these medullary lesions on the paraspinal muscles.

\section{MATERIALS AND METHODS}

A total of 44 domestic rabbits (Oryctolagus cuniculus) were used. The age of the animals at time of surgery was 4 weeks and their weight was $850 \mathrm{~g}$. Two control groups consisted of a total of 12 animals in which the spinal cord was exposed but neural tissue was not damaged. In each control group, we used one of two different surgical approaches to the spinal cord. Both approaches included bilateral desinsertion of the paravertebral muscles, and they differed only in the manipulation of the posterior arches. Laminar perforation at three consecutive levels was performed in eight animals and partial laminectomy at a single level was performed in four. The two control groups were used to evaluate the effect of the surgical approach on the development of spinal deformities.

Medullary lesions were performed on a total of 32 animals, divided into three groups. A unilateral lesion of the posterior horn and the dorsal column of the spinal cord was performed between the T7 and T11 levels, using three different techniques. In Group A (11 animals), the medullary lesion was performed using laser, which damaged the spinal cord through laminar perforations. In Group B (11 animals), stereotaxic electromicrocoagulation was performed, using the same surgical approach. A small electrode was introduced into the spinal cord through the laminar perforations. In Group 
C (ten animals), the medullary lesion was produced with longitudinal electrocoagulation, using partial laminectomy at a single level as the approach to the medullary canal. An L-shaped modification of the distal extreme of the electrode permitted a more extensive neural damage, over approximately $1 \mathrm{~cm}$.

For the laser procedure, a $\mathrm{CO}_{2}$ Surgical Laser, System 450 (Coherent Medical Division, Palo Alto, CA) was used. Because medullary tissue is fragile, the intensity used did not exceed $10 \mathrm{~W}$, and the exposure time was 0.1 second. Electric coagulation was done with a 0.5-mm electrode that was completely insulated, except at the tip. One end was connected to an electrocoagulator Grass Lesion Mark 4 (Grass Instruments Co.). An electric current of 20 ma at 15V was applied for 20 seconds.

To evaluate the development of scoliosis, we made roentgenograms immediately after operation and every 2 weeks until the animals were killed, 8 weeks after surgery. We used the method of $\mathrm{Cobb}^{3}$ to measure the degree of scoliotic curve. All animals were assessed clinically for evidente of neurologic alterations during the survival period. One week before we killed the rabbits, we performed an electrophysiological study of the paraspinal muscles at the apex of the curve in Group $\mathrm{C}$ and control animals. This study included electromyography (EMG) and analysis of the tonic-vibratory reflex. ${ }^{6}$ In rabbits without scoliotic curves, the muscles at the middle level of the surgical exposure were investigated.

The animals were killed with acetic formol salive perfusion. A detailed dissection of the spine was carried out to evaluate morphologic features and to detect any additional damage to the spinal cord. After it was removed, the spinal cord was embedded in paraffin wax blocks, and transverse, 8- $\mu$ m sections were made. The tissue sections were stained with hematoxylin and eosin (H\&E), Nissl's method, and Luxol fast blue (Lfb). The latter stains mainly the white medullary substance and permits the study of lesions involving intramedular neural pathways.

\section{RESULTS}

\section{Control Groups}

All animals in the control groups survived the entire period of study, 8 weeks. Scoliotic curves were not detected in any of these animals 8 weeks after surgery. A slight restoration of the physiologic kyphosis was noted in animals in which the posterior vertebral arches were manipulated with partial laminectomy. No signs of denervation, such as spontaneous activity or alterations in the morphologic features and characteristics of the motor unit potentials, were noted on EMG study. Comparative study of the muscular activity on both sides of the spine showed no difference in the amplitude of the potentials. In addition, no asymmetric response in the tonic - vibratory reflex was detected. The morphologic features and architectural configuration of the neural tissue of the spinal cord were similar to those described by Zeman and Imnes ${ }^{23}$ and Gurpide ${ }^{5}$ in their anatomic studies of normal rabbits. These results prove that the two different approaches performed on the spine (laminar perforations and partial laminectomy) did not induce scoliosis or cause medullary damage. 


\section{Laser Group}

Ten of 11 rabbits in the laser group survived for 8 weeks after surgery and one died 24 hours after surgery. At the final radiographic examination, scoliotic curves were detected in six of the ten animals (Table 1 ). The average curvature was $27^{\circ}$ (range, $12-$ $\left.68^{\circ}\right)$.

All curves were convex toward the damaged side. The major development of the curves was observed during the first 4 weeks after surgery, with the same degree of deformity remaining until the animals were killed (Figure 1). Kyphosis was detected in the lateral radiographs in all animals with scoliosis (Figure 2). The severity of the kyphosis was directly related to the degree of the scoliotic curve. The apex of the curve was located at the middle level of the operated vertebral segments. Based on morphologic study, all of these animals had true structural scoliotic curves, with marked wedging and rotation of the vertebral bodies.

Histologic examination of the spinal cord revealed medullary damage only in the six rabbits that developed scoliosis. In all of these, the lesions extended throughout the posterior horn and the nearest parts of the dorsal and lateral columns, with different degrees of damage (Figure 3). In three rabbits there was damage to the small intermediate lateral horn. Additional anterior horn damage was found in only two rabbits, both with similar characteristics. These two rabbits developed scoliotic curves of different magnitude $\left(68^{\circ}\right.$ and $\left.14^{\circ}\right)$, with the more severe curve in the one with the greatest damage to the dorsal column. It was impossible to correlate degree of scoliosis with morphologic features of the spinal cord lesions.

\section{Stereotaxic Electromicrocoagulation Group}

All 11 rabbits in the stereotaxic electromicrocoagulation group survived for 8 weeks after surgery. None exhibited neurologic disorders, such as motor or sensory deficiencies. At the end of the follow-up period, six rabbits had no scoliosis and five had developed scoliotic curves of only $8-12^{\circ}$ (mean, $9^{\circ}$ ) (Table 2). In two rabbits with scoliosis, the lateral radiographs revealed an increase of physiologic kyphosis, coinciding with the damaged level. In the other three rabbits, a restoration of the physiologic thoracic curvature was observed on the operated vertebral segments. EMG was not performed in this group.

Histopathologic examination revealed that only the animals with scoliosis had diverse lesions on the spinal cord, as in the laser group. The magnitude of the histologic damage could not be determined with certainty in two of the animals, due to artifacts in the sections. The few lesions clearly detected included slight neuronal loss in Clarke's column and small gliosis reaction in the intermediate lateral horn at this level. All of these lesions were on the convex side. One rabbit also had anterior horn damage with neural loss, but this was not accompanied by increased progression of the scoliotic curve. 


\section{Longitudinal Electrocoagulation Group}

Three of ten rabbits in the longitudinal electrocoagulation group did not survive for the entire follow-up period: two died within 24 hours of surgery and one died, in septicemia, 8 days after surgery. Six of the remaining seven animals developed scoliosis, with a mean curve of $22^{\circ}$ (range, 14-62 ${ }^{\circ}$ ). Characteristics of the curves are presented in Table 3. The convexity was located toward the damaged side (Figure 4). On lateral radiographs, the two animals with the highest degree of scoliosis showed an accentuated kyphotic deformity. A lordotic pattern was detected in three other animals. In these animals, a fusion of the posterior arches at the level of the operated segments was observed when the spinal cord was removed for histological examination.

Electrophysiologic assessment of the paraspinal muscles at the level of the apex was performed only in this group. Denervation signs, such as fibrillation or positive potential, were not detected in any of these rabbits. However, during the postural maintenance phase, with the rabbit at rest, reduced muscular activity was recorded on the convex side (Figure 5). This asymmetric response became less apparent when the animal turned or made other voluntary motions. In addition, the application of vibratory stimulus to the spinous processes produced tonic muscular activity (tonic-vibratory reflex) on both sides, but with reduced amplitude in the muscles of the convex side. These findings suggest an interruption of the sensory afferences of the reflex are, which controls postural tone. Assessment of the one rabbit in this group without scoliosis did not reveal any abnormality.

Histologic examination of the spinal cord revealed that all of the lesions were composed of a necrotic area of variable extension that included the posterior horn, the dorsal column, and the adjacent portion of the lateral column. Sometimes, areas of considerable glial reaction and inflammatory focal lesions were also seen. Anterior horn damage of different severity was detected in two rabbits but could not be related to the degree of scoliosis. In one rabbit, the anterior horn damage was on the contralateral side. It is possible that the electrode was placed deeper in the spinal cord of this rabbit, but the scoliosis also became convex toward the side of the dam-aged dorsal column.

\section{DISCUSSION}

In this study, the development of scoliosis was closely related to the inflicted medullary damage. Histologic lesions of the spinal cord were found only in rabbits that developed scoliosis, and all rabbits with spinal cord damage developed scoliosis. The posterior horn and the dorsal column were the areas mainly affected. These areas are composed of pathways that mediate different sensory impulses. This suggests a direct relationship between posterior damage of the spinal cord and the development of scoliotic curves. The same pathogenic mechanism proposed by Liszka, ${ }^{8}$ Mac-Ewen, ${ }^{10}$ and Pincott et al ${ }^{15}$ would explain the scoliosis induced in our animals. According to these authors, the interruption of the sensory afferent input to the spinal cord would induce an asymmetric loss of proprioception in the muscles innervated by those medullary segments, consequently a spinal muscular imbalance would cause the development of a scoliotic curve during the growth period. 
The presence of anterior horn damage was not correlated to the development of a scoliotic curve. The EMG study confirmed that the curve could not be attributed to a paralytic state. This same observation was reported by Pincott and Taffs, ${ }^{14}$ in primates that developed scoliosis after inoculation with poliomyelitis virus. In their study, the anterior horn damage was not significantly different between primates with and primates without scoliosis. The only difference was the presence of damage to the posterior horn, dorsal column, and Clarke's column in the animals with scoliosis. In all of these animals, the convexity of the curve was developed toward the side with the greater posterior spinal cord damage. The authors suggested an alteration in afferent sensory input as a pathogenic mechanism. This was also proposed by Liszkas and MacEwen. ${ }^{10}$

Electrophysiologic assessment of the paraspinal muscles in the rabbits that had scoliosis induced by longitudinal electrocoagulation showed an interruption of the tonic vibratory reflex at the level of the apex in the convex side. This reflex involves some of the same afferences as the stretching phasic reflex. ${ }^{18}$ In addition, there was decreased muscular activity on the convex side. These findings suggest that the central coactivation of the alpha and gamma motor neurons is intact but the postural tone modulation, which has a reduction in afferences, is not. Consequently, there was normal voluntary muscular activity mediated by the pyramidal pathway, but abnormal proprioceptive input.

In accordance with Hoogmartens and Basmajian, ${ }^{7}$ who found depressed response of the tonic - vibratory reflex on the convex side in patients with idiopathic scoliosis, Trontelj et $\mathrm{al}^{19}$ proposed that this asymmetry is due to a primary neurologic lesion of the spinal cord, which would be capable of inducing scoliosis. However, in our rabbits, we did not find a direct relationship between the extension of medullary damage and the degree of scoliotic curve. This may be due to the great variability of associated lesions in other areas, such as the lateral column, the intermediate lateral horn, the periependimary grey substance, the anterior horn, etc. It was not possible to evaluate the importance of each of the damaged areas for the progression of scoliosis.

The fact that the rabbits that had stereotaxic microcoagulation showed a lower degree of scoliosis suggests that the lesions may not have been sufficient to produce sensory deprivation capable of inducing muscular imbalance on the spine. Pincott et $\mathrm{al}^{15}$ proposed that in the presence of focal and unisegmental lesions with sensory deprivation, a compensatory neural or muscular mechanism may exist in the adjacent segments. When the deprivation is more extensive, this compensatory capacity would be insufficient, resulting in earlier development of scoliosis. This hypothesis can be supported from an anatomic point of view, because many of the medullary sensory afferences are multisegmental. ${ }^{11}$

The total percentage of scoliotic curves induced by our medullary damage techniques was slightly higher than that obtained by Alexander et ${ }^{1}{ }^{1}$ who used posterior rhizotomy, and similar to that reported by De Salis, ${ }^{4}$ who used intercostal arterial coagulation. In the latter work, all animals that developed scoliosis by vascular damage showed necrotic areas located in the posterior horn and the dorsal column of the spinal cord in the convex side. In addition, the severity of these lesions showed a clear relationship to the degree of scoliotic curve. 
We therefore conclude that unilateral loss of proprioceptive neural impulses caused by medullary damage can induce scoliosis. The convex side is located toward the side of the spinal cord damage. Muscular imbalance could be the inducing mechanism, as was confirmed in the bioelectrical study. These conclusions are consistent with previous experimental work and clinical observations that suggest that deficits of sensory proprioception may be one origin of "idiopathic" scoliosis.

Further studies should be designed to investigate selective lesions of different neural pathways of the spinal cord for the development of scoliosis, with attention directed to the role of the central nervous system as the modulator of all sensory input.

\section{REFERENCES}

1. Alexander MA, Bunch WF, Ebbesson SOE: Can experimental dorsal rhizotomy produce scoliosis? J Bone Joint Surg 55A:1509-1513, 1972

2. Barrack RL, Whitecloud ST, Burke SW, Cook SD, Harding AF: Proprioception in idiopathic scoliosis. Spine 9:681-685, 1984

3. Cobb JR: Outline for study of scoliosis: Instructional course lectures. Am Acad Orthop Surg 5:261-275, 1948

4. De Salis JA: Escoliosis experimental por lesión vascular. Doctoral Thesis, University of Navarra, Spain, 1977

5. Gurpide C: Comportamiento de la médula en la escoliosis experimental. Doctoral Thesis, University of Navarra, Spain, 1980

6. Hagbarth KE: The effect of muscle vibration in normal man and in patients with motor disorders. In: New Developments in EMG and Clinical Neurophysiology. Vol 3. Edited by JE Desmedt. Basel, Karger, 1973, pp 428-443

7. Hoogmartens MJ, Basmajian JV: Postural tone in the deep spinal muscles of idiopathic scoliosis patients and their siblings. Electromyogr Clin Neurophysiol 16:93-114, 1976

8. Liszka O: Spinal cord mechanisms leading to scoliosis in animal experiments. Acta Med Pol 2:45-63, 1961

9. Lloyd-Robert GC, Pincott JR, McMeniman P, Bayley IJL, Kendall 13: Progression in idiopathic scoliosis: A preliminary report of a possible mechanism. J Bone Joint Surg 60B:451-460, 1978

10. MacEwen GD: Experimental scoliosis. Clin Orthop 93:69-74, 1973

11. Mumenthaler M, Schiliack H: Patología de los Nervios Periféricos. Diagnostico y Tratamiento. Barcelona, Toray SA, 1976, pp 109

12. Nachemson A, Sahlstrand T: Etiologic factors in adolescent idiopathic scoliosis. Spine 2:176-184, 1977

13. Pincott JR: Observations on the afferent nervous system in idiopathic scoliosis. pp 45-59. Scoliosis 1979. Edited by PA Zorab, Siegler. New York, Academie Press, 1980

14. Pincott JR, Taffs LF: Experimental scoliosis in primates: A neurological cause. J Bone Joint Surg 64B:503-507, 1982

15. Pincott JR, Davies JS, Taffs LF: Scoliosis caused by section of dorsal spinal nerve roots. J Bone Joint Surg 66B:27-29, 1984

16. Sahlstrand T, Ortengren R, Nachemson A: Postural equilibrium in adolescent idiopathic scoliosis. Acta Orthop Scand 49:354-365, 1978 
17. Sahlstrand T, Petruson B, Ortengren R: Vestibulo-spinal reflex activity in patients with idiopathic scoliosis. Acta Orthop Scand 50:275-281, 1979

18. Stalberg E, Trontelj JV: Single Fiber Electromyography. Old Woking, Mirvalle Press, 1979

19. Trontelj JV, Pecak F, Dimitrijevik MR: Segmental neurophysiological mechanisms in scoliosis. J Bone Joint Surg 61B:310-313, 1979

20. Yamada K, Yamamoto H, Tamura T, Tezuka A: Development of scoliosis under neurological basis, particularly in relation with brain-stem abnormalities. J Bone Joint Surg 56A:1764, 1974

21. Yamamoto H: A postural dysequilibrium as an etiological factor in idiopathic scoliosis. Presented at the Seventeenth Annual Meeting of the Scoliosis Research Society, Denver, Colorado, 1982

22. Yekutiel M, Robin GC, Yarom R: Proprioceptive function in children with adolescent idiopathic scoliosis. Spine 6:560-566, 1981

23. Zeman W, Imnes JR: Craigie's Neuroanatomy of the Rat. New York, Academic Press, 1963, pp 50-60 


\begin{tabular}{|c|c|c|c|c|}
\hline \multicolumn{4}{|c|}{ Table 1. Characteristic of Scoliotic Curves: Laser Group } \\
\hline \multirow{2}{*}{ Rabbit } & Scoliosis & \multirow{2}{*}{ Lateral view } & Complications \\
\cline { 2 - 4 } & Level & Degree & Kyphosis & \\
\hline 1 & T7-T11 & 44 & & \\
\hline 2 & Nonscoliotic & & & \\
\hline 3 & Nonscoliotic & & Kyphosis & \\
\hline 4 & T7-T11 & 68 & Kyphosis & \\
\hline 5 & T9-L1 & 14 & Kyphosis & \\
\hline 6 & T6-T11 & 12 & Paraplegia* \\
\hline 7 & & & & \\
\hline 8 & T7-T11 & 12 & & \\
\hline 9 & T7-T10 & 14 & Kyphosis & \\
\hline 10 & Nonscoliotic & & & \\
\hline 11 & Nonscoliotic & & & \\
\hline \multirow{2}{*}{$*$ Died 24 hours after surgery. } & & & \\
\hline
\end{tabular}

\begin{tabular}{|c|c|c|c|}
\hline \multicolumn{4}{|c|}{ Table 2. Characteristics of Scoliotic Curves: Stereotaxic } \\
Electromicrocoagulation Group \\
\hline \multirow{2}{*}{ Rabbit } & \multicolumn{2}{|c|}{ Scoliosis } & \multirow{2}{*}{ Lateral view } \\
\cline { 2 - 3 } & Level & Degree & Rectification (*) \\
\hline 12 & T8 - T11 & 8 & \\
\hline 13 & Nonscoliotic & & Rectification \\
\hline 14 & Nonscoliotic & & Kyphosis \\
\hline 15 & T7 -T12 & 10 & Kyphosis \\
\hline 16 & T8 -T11 & 8 & Rectification \\
\hline 17 & Nonscoliotic & & \\
\hline 18 & Nonscoliotic & & \\
\hline 19 & Nonscoliotic & & \\
\hline 20 & T7 - T10 & 8 & \\
\hline 21 & T2 -T9 & 12 & \\
\hline 22 & Nonscoliotic & & \\
\hline$*$ Rectification of the physiologic curvature. & \\
\hline
\end{tabular}




\begin{tabular}{|c|c|c|c|c|}
\hline \multicolumn{5}{|c|}{ Table 3. Characteristics of Scoliotic Curves: Longitudinal } \\
Electrocoagulation Group \\
\hline \multirow{2}{*}{ Rabbit } & Scoliosis & \multirow{2}{*}{ Lateral view } & Complications \\
\cline { 2 - 3 } & Level & Degree & & \\
\hline 23 & T7-T10 & 16 & Lordosis & Paraplegia* \\
\hline 24 & - & & & \\
\hline 25 & T8-T11 & 18 & Lordosis & \\
\hline 26 & T7-T11 & 20 & Kyphosis & \\
\hline 27 & Nonscoliotic & & & \\
\hline 28 & T6-T9 & 62 & Kyphosis & \\
\hline 29 & - & & & Septicemia $\dagger$ \\
\hline 30 & T8-T11 & 14 & Rectification & \\
\hline 31 & T8-T11 & 14 & Rectification & \\
\hline 32 & - & & & Unknown* \\
\hline \multirow{2}{*}{$\begin{array}{l}\text { *Died 24 hours after surgery. } \\
\dagger \text { Died 8 days after surgery. }\end{array}$} \\
\hline
\end{tabular}




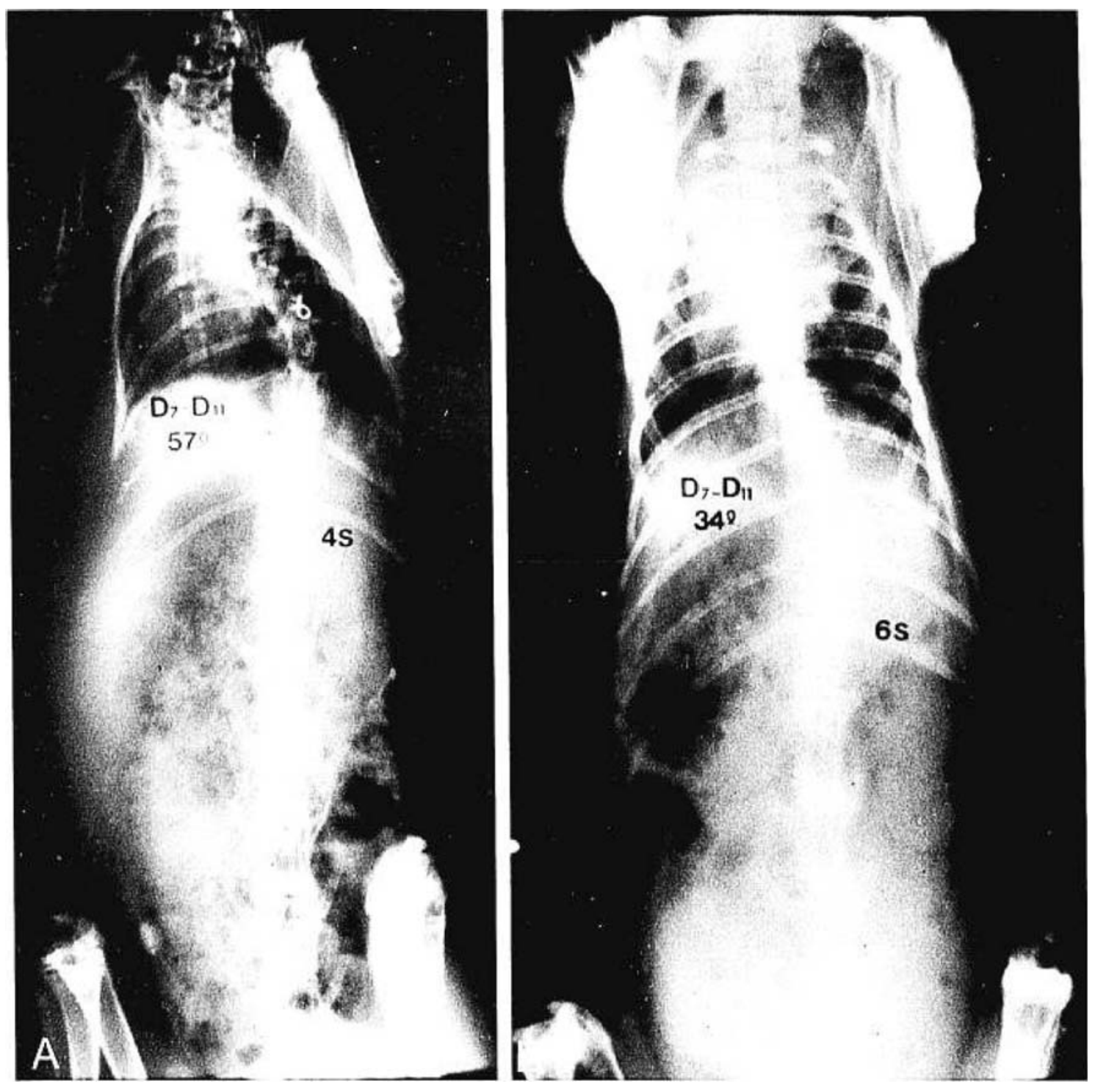

Figure 1. Anteroposterior roentgenograms showing the degree of scoliosis 4 weeks (A) and 6 weeks (B) after surgery in two rabbits with medullary damage induced with laser. 

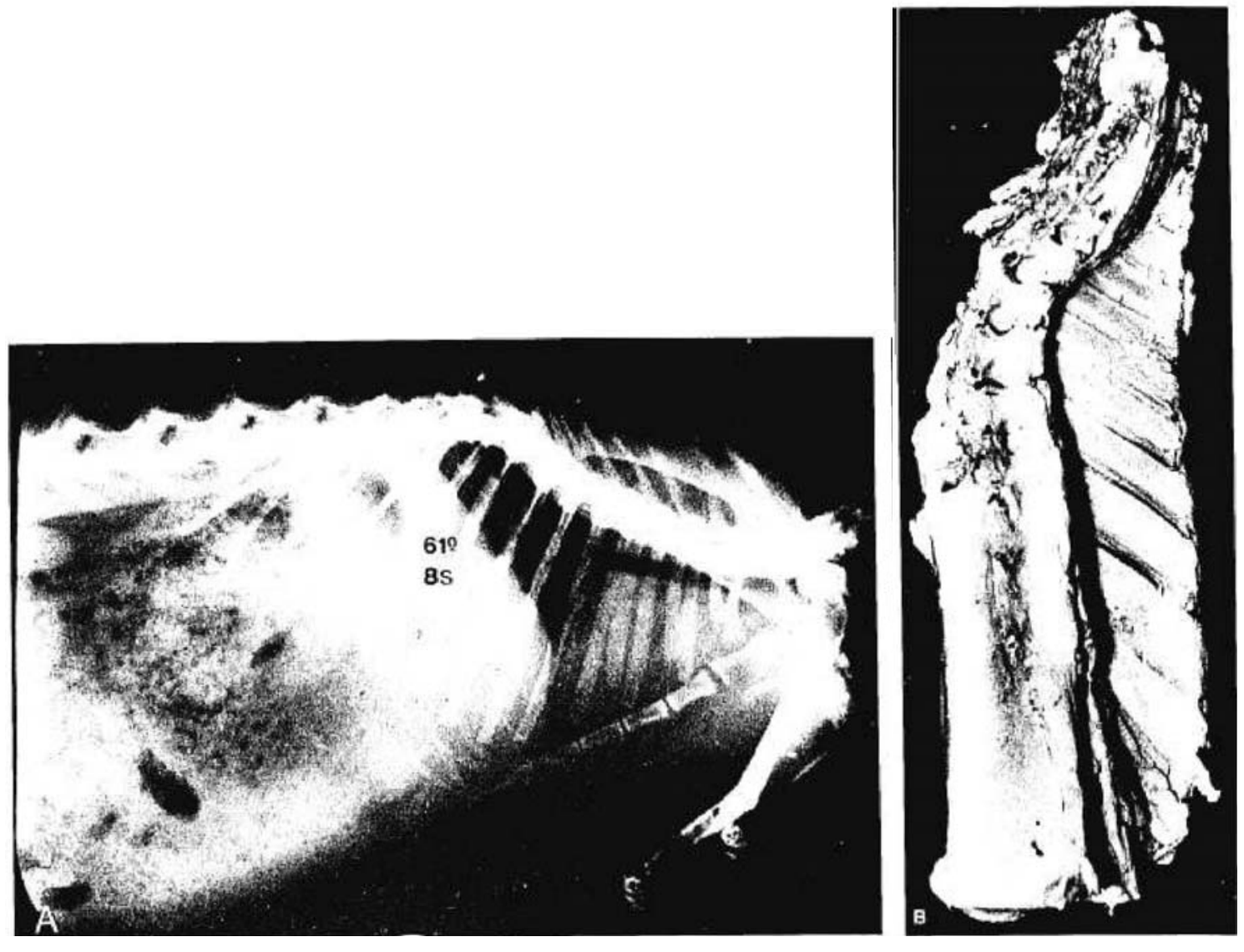

Figure 2. Rabbit 4, medullary damage induced with laser. A, Lateral roentgenogram, showing the severe dorsal kyphosis that accompanied scoliosis. B, Macroscopic detall of this kyphosis. The rib cage was removed to permit observation of the deformity. 


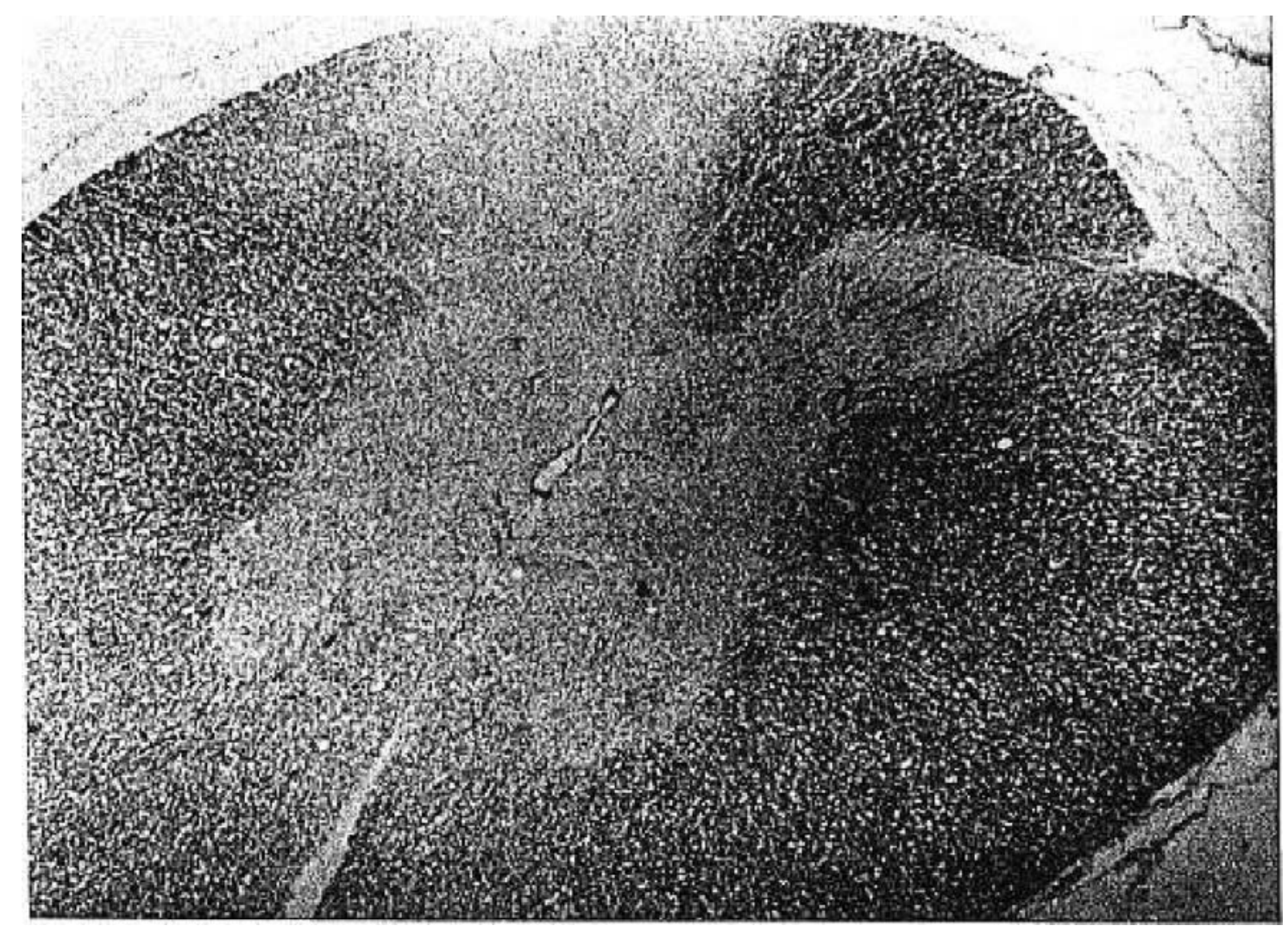

Figure 3. Rabbit 1, medullary damage induced with laser. Histologic section of the spinal cord at the level of the lesion. Note extensive affection of the white matter of the dorsal column. (Luxol fast blue, original magnification X15) 


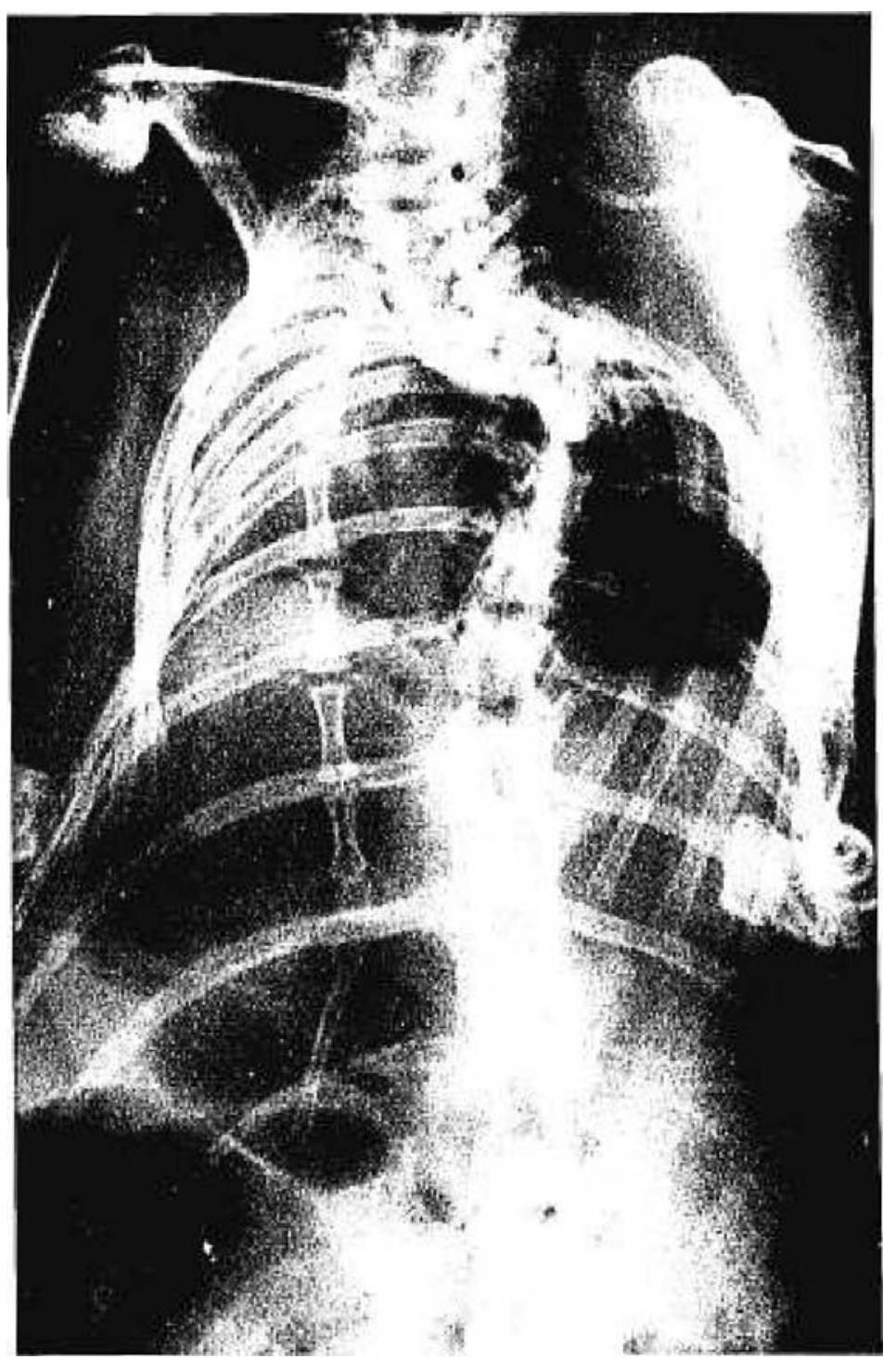

Figure 4. Rabbit 28, scoliosis induced with longitudinal electrocoagulation. Roentgenogram made 8 weeks after surgery. 


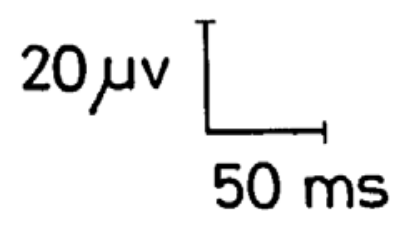

\section{convexity}

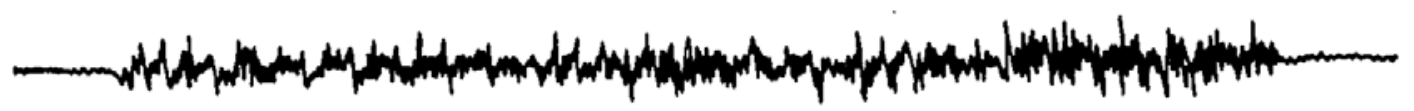

\section{concavity}

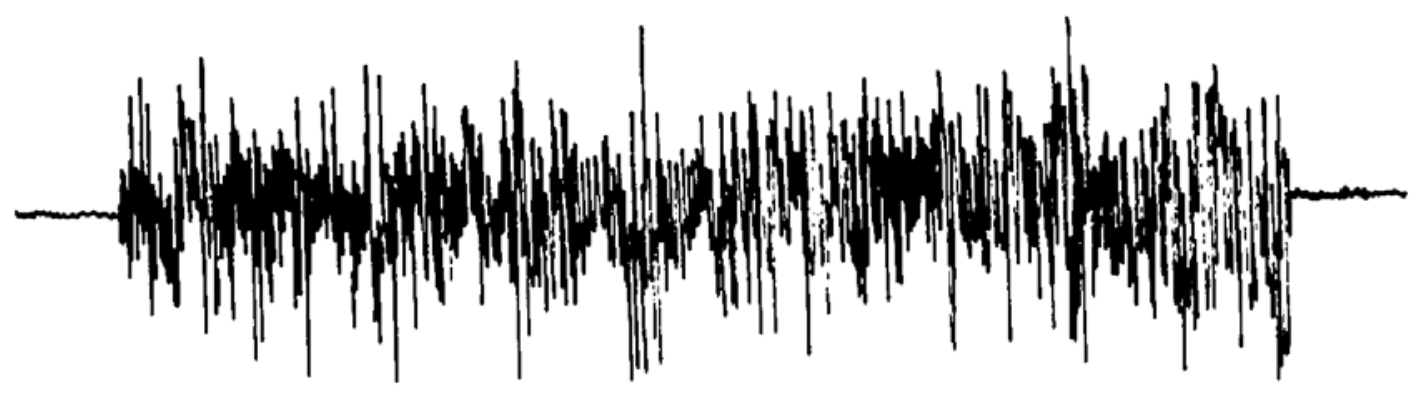

Figure 5. EMG study of the paraspinal muscles of rabbit 23. There is a lower postural activity in the muscles of the convex side. Registration performed with monopolar electrode. 